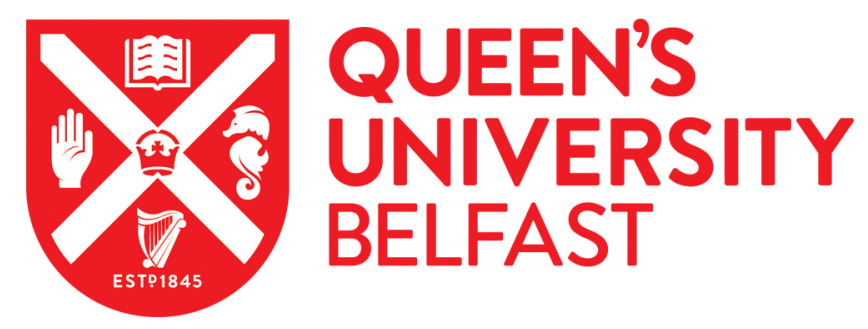

\title{
MgFeCe Ternary Layered Double Hydroxide as Highly Efficient and Recyclable Heterogeneous Base Catalyst for Synthesis of Dimethyl Carbonate by Transesterification
}

Nivangune, N. T., Ranade, V. V., \& Kelkar, A. A. (2017). MgFeCe Ternary Layered Double Hydroxide as Highly Efficient and Recyclable Heterogeneous Base Catalyst for Synthesis of Dimethyl Carbonate by

Transesterification. Catalysis Letters, 147(10), 2558-2569. https://doi.org/10.1007/s10562-017-2146-x

Published in:

Catalysis Letters

Document Version:

Peer reviewed version

Queen's University Belfast - Research Portal:

Link to publication record in Queen's University Belfast Research Portal

\section{Publisher rights}

Copyright 2017 Springer Verlag. This work is made available online in accordance with the publisher's policies. Please refer to any applicable terms of use of the publisher.

\section{General rights}

Copyright for the publications made accessible via the Queen's University Belfast Research Portal is retained by the author(s) and / or other copyright owners and it is a condition of accessing these publications that users recognise and abide by the legal requirements associated with these rights.

Take down policy

The Research Portal is Queen's institutional repository that provides access to Queen's research output. Every effort has been made to ensure that content in the Research Portal does not infringe any person's rights, or applicable UK laws. If you discover content in the Research Portal that you believe breaches copyright or violates any law, please contact openaccess@qub.ac.uk. 


\title{
MgFeCe ternary layered double hydroxide as highly efficient and recyclable heterogeneous base catalyst for synthesis of dimethyl carbonate by transesterification
}

\author{
Nayana T. Nivangune, ${ }^{a}$ Vivek V. Ranade, ${ }^{b^{*}}$ Ashutosh A. Kelkar ${ }^{a^{*}}$ \\ ${ }^{a}$ Chemical Engineering and Process Development (CEPD) Division, National Chemical Laboratory, Pune 411008, \\ India.E-mail: aa.kelkar@ncl.res.in

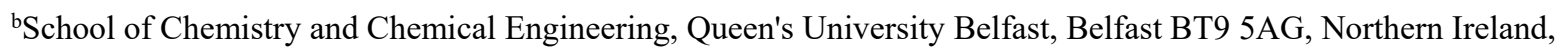 \\ UK.E-mail:V.Ranade@qub.ac.uk
}

\begin{abstract}
A series of $\mathrm{Mg}_{3}: \mathrm{Fe}_{\mathrm{x}}+\mathrm{Ce}_{1-\mathrm{x}}$ LDHs (3:1) were synthesized by co-precipitation method by varying molar ratio of Fe:Ce between 1:0 to 0:1 ( LDH-1 to LDH-6). All synthesized LDHs were characterized by XRD, FT-IR, TEM, N2 sorption, benzoic acid titration and XPS in detail and evaluated for selective synthesis of dimethyl carbonate by transesterification of ethylene carbonate with methanol. It was demonstrated that the structural and basic properties of synthesized LDHs were strongly dependent on the Fe:Ce molar ratio (Ce concentration). The correlation between their physicochemical properties and catalytic performance was studied in detail. Among all synthesized LDHs the best result was obtained with LDH-3 (Fe:Ce=0.85:0.15) where LDH structure remained intact, and showed high number of strong basic sites on LDH surface. LDH-3 was recycled 7 times while maintaining high catalyst activity and selectivity towards DMC. The obtained results elucidate the important role of $\mathrm{Ce}$ in modifying the basic properties of LDH in enhancing the catalytic activity for DMC synthesis.
\end{abstract}




\section{Graphical abstract}

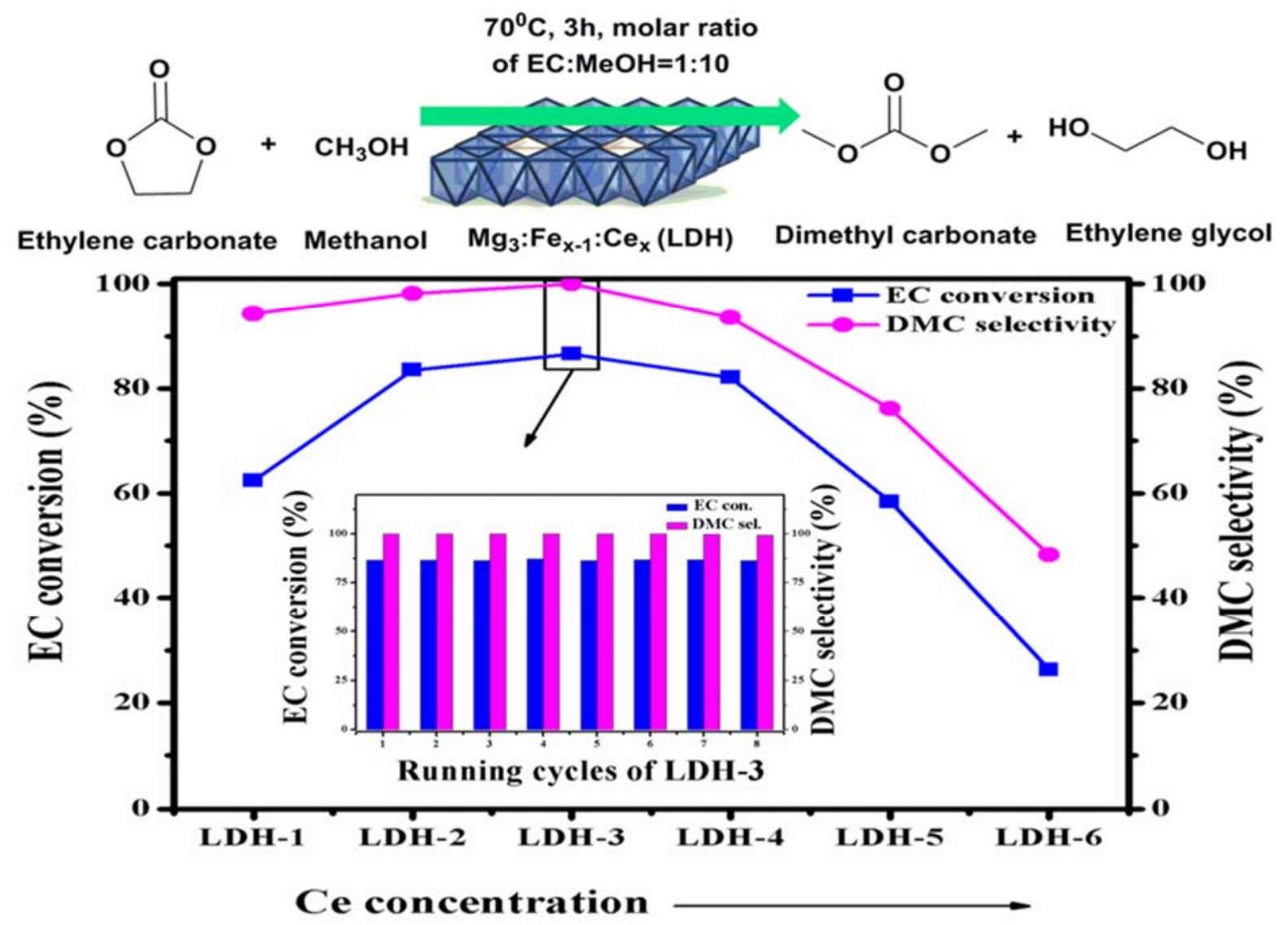

\section{Keywords}

Dimethyl carbonate. Ethylene carbonate. $\mathrm{Mg}$-Fe-Ce ternary hydrotalcite. Transesterification 


\section{Introduction}

Dimethyl carbonate (DMC) is an important chemical, which gained intense interest from scientific and industrial fields, due to its low toxicity and good biodegradability. DMC is being looked as a green chemical for the production of polycarbonate and other chemicals [1]. It is also used as a safe replacement for toxic phosgene in carbonylation and methylation reactions [2]. In addition DMC has potential applications as electrolyte in lithium batteries as a polar aprotic solvent and as an octane booster in gasoline to meet oxygenate specifications [3-5]. Conventionally DMC was synthesized via phosgenation [6] and presently manufactured by oxidative carbonylation of methanol [7]; both of these routes require corrosive and poisonous gases like chlorine, $\mathrm{COCl}_{2}$ and $\mathrm{CO}$. In case of oxidative carbonylation of methanol there is a risk associated with the explosion hazard of $\mathrm{CO} / \mathrm{O}_{2}$ mixture. One clean and sustainable route for the synthesis of DMC is the transesterification of cyclic carbonate [ethylene carbonate (EC)/propylene carbonate (PC)] with methanol [8]. This is a safe and atom efficient process and ethylene glycol is formed as the byproduct. Ethylene glycol is important chemical and also can be converted back to ethylene carbonate by reaction with urea [9]. Significant work is being carried out on the development of improved catalysts for the synthesis of DMC from EC and methanol. Simple inorganic, organic bases and ionic liquids (ILs) were found to be active catalysts for DMC synthesis; still applications are limited because of difficulties in catalyst-product separation due to its homogeneous nature [10-12]. Further Immobilization of the IL on different supports have been explored but high cost of catalyst has limited their application $[13,14]$. Considerable amount of work has been carried out on the development of heterogeneous catalysts for the synthesis of DMC. Heterogeneous catalysts based on mixed metal oxides [15-19], smectite [20], anion-exchange resin [21], Na-dawsonite [22], mesoporous graphitic carbon nitride [23] and Binary hydrotalcites (i.e LDHs) [24, 25] etc. have been studied for transesterification reaction. Recently Xu et al. reported 78\% DMC yield at $160^{\circ} \mathrm{C}$ in $6 \mathrm{~h}$ with meso structured graphitic carbon nitride (CN-MCF) catalyst [23]. The catalyst was recycled five times without significant loss in catalyst activity; however, harsh reaction conditions $\left(160^{\circ} \mathrm{C}\right.$ and $0.6 \mathrm{MPa} \mathrm{CO}_{2}$ pressure $)$ were necessary to achieve observed results. Among all heterogeneous catalysts investigated mixed metal oxides were found to be active catalysts for this reaction, however, they require either high reaction temperature $\left(100-160^{\circ} \mathrm{C}\right)$ or high catalyst loading (10-25 wt \%) [15-18]. The catalyst was recycled four to five times, but catalyst activation at high temperature was required in most of the cases during each recycle experiment. This 
potentially may cause problem in continuous or large scale operation. In this context it is still challenging task to develop heterogeneous catalysts exhibiting high catalyst activity and high stability for the synthesis of DMC from EC and methanol under mild reaction conditions. Hydrotalcites (HTs) or Layered double hydroxides (LDHs) constitute a class of layered compounds complementary to classic clays, as they contain positively charged layers and anions in the interlamellar space [26]. LDHs are widely studied and successfully used as basic catalysts for several reactions such as condensation, michael addition, transesterification, and alkylation etc [27]. From the literature it was observed that there are very limited reports on the use of binary LDHs/ HTs as catalysts for transesterification of EC with methanol. Bajaj et al. reported that the catalyst activity was influenced by $\mathrm{Mg}-\mathrm{Al}$ ratio and $\mathrm{Mg}-\mathrm{Al} \mathrm{LDH}$ with molar ratio of 5:1 showed maximum activity [25]. Unfortunately, significant decrease in activity was observed after fourth recycle due to structural changes in catalyst indicating lower stability of the catalyst. According to Watanabe et al. basicity (-OH sites) of LDH plays an important role in this transestrification reaction [24]. $\mathrm{Mg}-\mathrm{Al} \mathrm{LDH}$ with excess amount of - $\mathrm{OH}$ anions was found to be an effective catalyst for DMC synthesis. It is well known that basicity of LDH can be tuned by proper choice of M (II) and $\mathrm{M}(\mathrm{III})$ metal cations or by varying the molar ratio of $\mathrm{M}(\mathrm{II}) / \mathrm{M}(\mathrm{III})[25,28,29]$. Recently incorporation of third metal cation in parent LDH has attracted much more attention with the aim of modifying basicity of the catalyst. Recently Zhang et al. [30] have reported the synthesis of $\mathrm{Mg} / \mathrm{Fe}+\mathrm{Ce}-\mathrm{CO}_{3}$ ternary $\mathrm{LDH}$ for the first time, however, many important details on characterization are lacking and its catalytic applications have not been investigated.

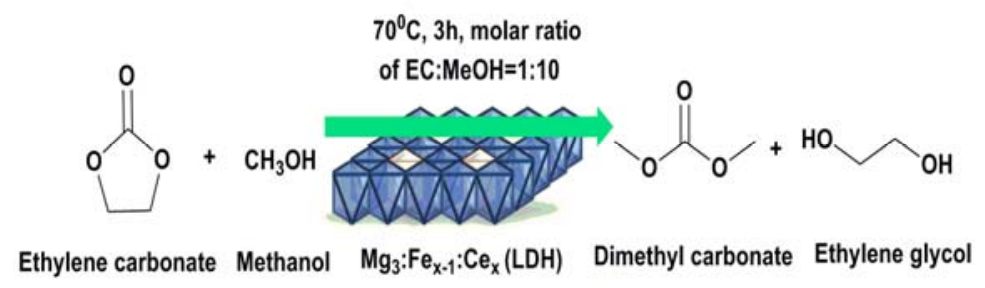

Scheme 1: Schematic diagram of synthesis of dimethyl carbonate from ethylene carbonate and methanol over layered double hydroxide (LDHs).

In this work we have synthesized a series of $\mathrm{Mg}_{3} \mathrm{Fe}_{\mathrm{x}} \mathrm{Ce}_{1-\mathrm{x}}$ ternary $\mathrm{LDHs}$, by varying molar ratio of Fe:Ce. All synthesized LDHs were characterized in detail by various spectroscopic techniques. Influence of $\mathrm{Ce}$ and its concentration on the properties and catalytic activity of 
$\mathrm{Mg}_{3}$ : Fe layered double hydroxide $\left(\mathrm{Mg}_{3} \mathrm{Fe}_{\mathrm{x}} \mathrm{Ce}_{1-\mathrm{x}}\right)$ for $\mathrm{DMC}$ synthesis (scheme 1) was investigated in detail. Ceria has lower electronegativity compared to Fe and incorporation of $\mathrm{Ce}$ in the $\mathrm{Mg}_{3}-\mathrm{Fe} \mathrm{LDH}$ could result in increase in the basicity of $\mathrm{Mg}_{3} \mathrm{Fe}_{\mathrm{x}} \mathrm{Ce}_{1-\mathrm{x}} \mathrm{LDHs}$ and better activity towards DMC synthesis. With this idea in mind the present work on the synthesis of $\mathrm{Mg}_{3} \mathrm{Fe}_{\mathrm{x}} \mathrm{Ce}_{1-\mathrm{x}}$ ternary LDHs was initiated. To the best of our knowledge, this is the first report on the use of Ternary LDHs $\left(\mathrm{Mg}_{3} \mathrm{Fe}_{\mathrm{x}} \mathrm{Ce}_{1-\mathrm{x}}\right)$ as a catalyst for the synthesis of DMC from EC and methanol.

\section{Experimental}

\subsection{Catalyst preparation}

A series of $\mathrm{Mg}_{3} \mathrm{Fe}_{\mathrm{x}} \mathrm{Ce}_{1-\mathrm{x}} \mathrm{LDHs}$ were synthesized by co-precipitation method followed by hydrothermal treatment. The $\mathrm{Mg}: \mathrm{Fe}+\mathrm{Ce}$ molar ratio was kept constant at 3:1; while $\mathrm{Fe}: \mathrm{Ce}$ molar ratio was varied (1:0 to 0:1). In a typical procedure solution A was prepared by dissolving desired amount of $\mathrm{Mg}\left(\mathrm{NO}_{3}\right)_{2} .6 \mathrm{H}_{2} \mathrm{O}, \mathrm{Fe}\left(\mathrm{NO}_{3}\right)_{3} .9 \mathrm{H}_{2} \mathrm{O}$ and $\mathrm{Ce}\left(\mathrm{NO}_{3}\right)_{3} .6 \mathrm{H}_{2} \mathrm{O}$ in deionized water and solution $\mathrm{B}$ was prepared by dissolving $\mathrm{NaOH}$ and $\mathrm{Na}_{2} \mathrm{CO}_{3}(2 \mathrm{M})$ in deionized water. Solutions A and B were added simultaneously while $\mathrm{pH}$ of the resultant solution was maintained at 10-11 with constant stirring at room temperature. The gel obtained was hydrothermally treated at $90^{\circ} \mathrm{C}$ for $15 \mathrm{~h}$. Then the precipitate was filtered, washed several times with deionized water till filtrate became neutral. Finally, the synthesized ternary LDHs were dried at $100^{\circ} \mathrm{C}$ for $12 \mathrm{~h}$ in air. LDHs prepared with different Fe:Ce molar ratios 1:0, 0.95:0.05, 0.85:0.15, 0.75:0.25, 0.55:0.45, and 0:1 were named as LDH-1, LDH-2, LDH-3, LDH-4, LDH-5 and LDH-6 respectively.

Elemental chemical compositions of $\mathrm{Mg}_{3} \mathrm{Fe}_{\mathrm{x}} \mathrm{Ce}_{1-\mathrm{x}} \mathrm{LDHs}$ were determined with the help of ICP-OES method (Table S1). Metal composition in all "neat" LDH samples, was found to be in good agreement with the values based on compositions used for the preparation. Various ternary $\mathrm{Mg}_{3} \mathrm{Fe}_{0.85} \mathrm{M}_{0.15}$ LDHs were prepared by same method by varying $\mathrm{M}(\mathrm{III})$ [where M(III) = La, Sm, Y and Cr]. See supporting information for the details of synthesis and characterization of $\mathrm{Mg}_{3} \mathrm{Fe}_{0.85} \mathrm{M}_{0.15} \mathrm{LDHs}$ (Page S3).

\subsection{Catalyst characterization}


X-ray diffraction (XRD) patterns were recorded on a P Analytical PXRD system (Model $\mathrm{X}$-Pert PRO-1712), using Ni filtered $\mathrm{Cu} \mathrm{K} \alpha$ radiation $(\lambda=0.154 \mathrm{~nm})$ as an X-ray source (current intensity, $30 \mathrm{~mA}$; voltage, $40 \mathrm{kV}$ ) and an X-accelerator detector. The samples were scanned in a $2 \theta$ range of $10-80^{\circ}$.

FT-IR spectra were recorded on a Shimadzu 8201 spectrophotometer in $400-4000 \mathrm{~cm}^{-1}$ region. The samples were diluted prior to measurement with $\mathrm{KBr}$ in a 2/98 mixture ratio. Transmission electron microscopy (TEM) analysis was performed on a Jeol Model JEM 1200 electron microscope operated at an accelerating voltage of $120 \mathrm{kV}$. A small amount of specimen was prepared by ultrasonically suspending the powder sample in IPA, and drops of the suspension were deposited on a carbon coated copper grid dried at room temperature before analysis.

The $\mathrm{N}_{2}$ adsorption-desorption isotherms at $-196^{\circ} \mathrm{C}$ were obtained using a Thermo surfer BET instrument and the surface areas were deduced using the BET equation. Before analysis, the samples were out gassed at $100^{\circ} \mathrm{C}$ for $6 \mathrm{~h}$.

The basic properties were determined by titration with $0.01 \mathrm{M}$ benzoic acid solution in toluene using $0.15 \mathrm{~g}$ of vacuum dried solid sample suspended in $2 \mathrm{~mL}$ of indicator solution. Indicator solution for the determination of weak basic sites $(\mathrm{pKa}=7.1)$ contained $0.01 \mathrm{~g}$ of Bromothymol blue in $100 \mathrm{~mL}$ toluene. The amount of strong basic sites $(\mathrm{pKa}=9.3)$ were determined in the presence of an indicator solution containing $0.01 \mathrm{~g}$ of Phenolphthalein in $100 \mathrm{~mL}$ toluene [31, 32].

XPS spectra were recorded on a VG Microtech Multilab ESCA3000 spectrometer equipped with non-monochromatised $\mathrm{Mg}-\mathrm{K} \alpha$ radiations $(\mathrm{hv}=1253.6 \mathrm{eV})$.

\subsection{Catalytic Tests}

The transesterification of ethylene carbonate with methanol over the Ce incorporated ternary LDHs was performed in a $50 \mathrm{ml}$ jacketed glass reactor equipped with magnetic stirrer and reflux condenser. Typically, the reactor was charged with $23 \mathrm{mmol}$ of ethylene carbonate, $230 \mathrm{mmol}$ of methanol and $2.5 \mathrm{wt} \%$ of $\mathrm{LDH}$ catalyst (relative to EC). The reaction was carried out at $70^{\circ} \mathrm{C}$ for $3 \mathrm{~h}$ reaction time under vigorous stirring. After $3 \mathrm{~h}$ of the reaction, the glass reactor was cooled to room temperature; the solid catalyst was separated from the solution by filtration. Sample was analyzed by gas chromatography to 
monitor the progress of the reaction. The gas chromatograph (Agilent $6890 \mathrm{~N}$ ) was equipped with an FID detector and an innowax capillary column (30 m length $\times 0.53 \mathrm{~mm}$ ID $0.25 \mu \mathrm{m}$ film thickness). Formation of HEMC (2-Hydroxy ethyl methyl carbonate, intermediate product), DMC and EG as products were confirmed by GC-MS. Activity of the catalyst was based on conversion of limiting reagent under standard reaction conditions. Stability and leaching of LDHs was investigated under optimized reaction conditions (Page S4).

\section{Results and discussion}

\subsection{Powder X-ray diffraction}

The XRD patterns of all synthesized ternary $\mathrm{Mg}_{3} \mathrm{Fe}_{\mathrm{x}} \mathrm{Ce}_{1-\mathrm{x}} \mathrm{LDHs}$ with different Fe:Ce molar ratios are shown in Fig. 1. LDH-1 to LDH-3 showed typical features of highly crystalline LDH materials with an R3m rhombohedral space group symmetry [33, 34]. No other phase was detected in these samples indicating that cerium species are successfully incorporated into LDHs. Nevertheless, with increase in Ce concentration for LDH-4 to LDH-6 decrease in crystallinity (better ordering of brucite sheets) which is directly proportional to the peak intensity and sharpness of (003) and (006) planes; was observed. This is due to the substitution of $\mathrm{Fe}\left(0.65^{\circ} \mathrm{A}\right)$ by larger ionic radii of $\mathrm{Ce}\left(1.01^{\circ} \mathrm{A}\right)$, which inhibits the intercalation of $\mathrm{Ce}$ in $\mathrm{LDH}$ structure and also leads to significant distortion in the layers [35]. At higher $\mathrm{Ce}$ concentration ( $\mathrm{LDH}-6, \mathrm{Fe}: \mathrm{Ce}=0: 1)$ the layered structure collapsed completely and formation of phases like $\mathrm{Mg}(\mathrm{OH})_{2}(\mathrm{PCPDF}-86-0441), \mathrm{Ce}(\mathrm{OH})_{4}[36,37]$ and $\mathrm{Ce}_{2}\left(\mathrm{CO}_{3}\right)_{2}$. $(\mathrm{OH})_{2} \cdot \mathrm{H}_{2} \mathrm{O}$ (PCPDF-46-0369) was observed. The lower electronegativities of rare earth elements (REE), could favour formation of these species at the initial stage of precipitation [38].

The lattice parameters ' $a$ ' and 'c' were calculated and are summarized in Table 1. 


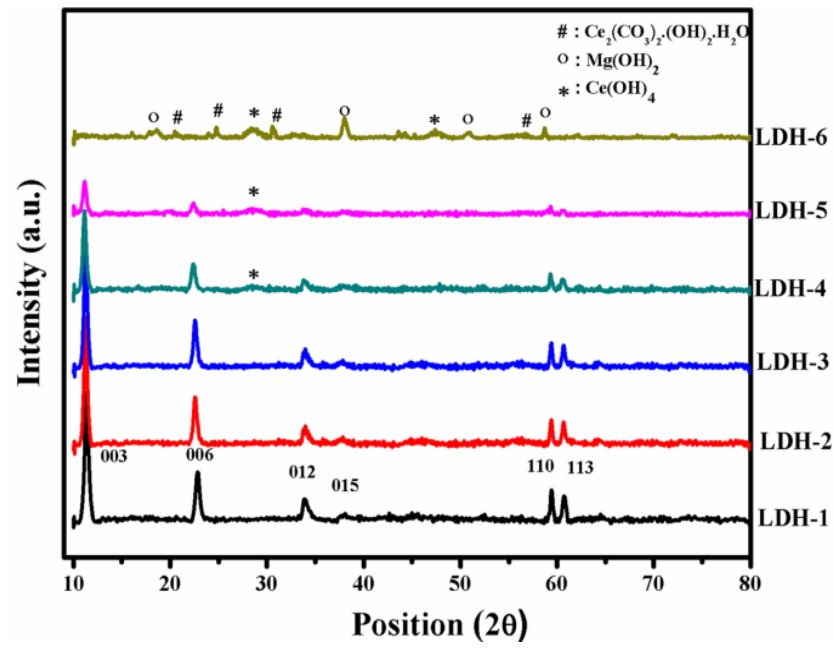

Fig. 1. XRD patterns of all synthesized $\mathrm{Mg}_{3} \mathrm{Fe}_{\mathrm{x}} \mathrm{Ce}_{1-\mathrm{x}} \mathrm{LDHs}$ (LDH-1 to LDH-6).

Table1. Characteristics of the prepared samples.

\begin{tabular}{|c|c|c|c|c|c|c|c|c|c|}
\hline \multirow[t]{2}{*}{ Sample } & \multicolumn{4}{|c|}{ Lattice parameters $\left(\mathrm{A}^{0}\right)$} & \multirow{2}{*}{$\begin{array}{c}\text { Surface } \\
\text { area } \\
\left(\mathrm{m}^{2} / \mathrm{g}\right)\end{array}$} & \multirow{2}{*}{$\begin{array}{c}\text { Pore } \\
\text { volume } \\
\left(\mathrm{cm}^{3} / \mathrm{g}\right)\end{array}$} & \multirow{2}{*}{$\begin{array}{c}\text { Pore } \\
\text { diameter } \\
(\mathrm{nm})\end{array}$} & \multicolumn{2}{|c|}{ Basic sites $\left(\times 10^{-4} \mathrm{~mole} / \mathrm{g}\right)$} \\
\hline & $\mathrm{d}(003)$ & $\mathrm{d}(110)$ & $\mathrm{a}$ & c & & & & $\begin{array}{c}\text { Weak } \\
\text { basic sites }\end{array}$ & $\begin{array}{c}\text { Strong } \\
\text { basic sites }\end{array}$ \\
\hline LDH-1 & 7.78 & 1.566 & 3.112 & 23.34 & 67 & 0.51 & 16.8 & 1.8 & 1 \\
\hline LDH-2 & 7.85 & 1.564 & 3.128 & 23.55 & 128 & 0.8 & 23 & 2.4 & 1.2 \\
\hline LDH-3 & 7.88 & 1.572 & 3.144 & 23.64 & 136 & 0.81 & 24.3 & 2.8 & 1.3 \\
\hline LDH-4 & 7.92 & 1.576 & 3.152 & 23.76 & 134 & 0.78 & 22.7 & 3.0 & 1.0 \\
\hline LDH-5 & 7.93 & 1.577 & 3.154 & 23.79 & 133 & 0.76 & 21.6 & 3.5 & 0.8 \\
\hline LDH-6 & nd & nd & nd & nd & 129 & 0.73 & 20.2 & 4.5 & 0.5 \\
\hline
\end{tabular}

nd: not detected

Parameter ' $\mathrm{a}$ ' $\left(\mathrm{a}=2 \mathrm{~d}_{110}\right)$ depends mainly on the average radius of the metal cation and reflected the density of metal ions in 110 plane. [35] The observed results may be due to the isomorphous substitution of $\mathrm{Fe}$ by $\mathrm{Ce}$ having larger ionic radii [39]. Thus more $\mathrm{Ce}$ insertion leads to an increase in average radius of cations in the layers and this leads to increase in 'a' parameter.

Parameter ' $c$ ' $\left(c=3 d_{003}\right)$ depends on the thickness of octahedral sheets, the anion size and their orientation within the interlayer space and the electrostatic attraction between different layers [40]. Lower polarizing ability of the Ce results in weak electrostatic interaction 
between the layer and interlayer anions and leads to increase in the layer spacing resulting in increase of the 'c' parameter value. Thus increase in values of parameters ' $a$ ' and ' $c$ ' with increase in Ce concentration (Table $1, \mathrm{LDH}-1<<\mathrm{LDH}-5$ ) may be attributed to larger ionic radii and lower polarizing ability of $\mathrm{Ce}[39,40]$.

\subsection{FT-IR spectroscopy}

The FT-IR spectral information can be used to determine the actual bonding type in the expected compounds and to determine the substitution of $\mathrm{Ce}$ in the brucite layer. FT-IR spectra of all LDH samples (Fig. 2) showed broad band centered around $3500 \mathrm{~cm}^{-1}$ due to the stretching mode of hydroxyl groups present in the brucite-like layers and from the interlayer water molecules of the hydrotalcite structure. The band at $3681 \mathrm{~cm}^{-1}$ was observed in LDH-4<< LDH-6; which is characteristic of non-hydrogen bound -OH group [41]. A weaker band at $1630 \mathrm{~cm}^{-1}$ is owing to the bending mode of water molecules. IR absorption bands at $1510 \mathrm{~cm}^{-1}, 1382 \mathrm{~cm}^{-1}\left(\mathrm{v}_{3}\right), 852 \mathrm{~cm}^{-1}\left(\mathrm{v}_{2}\right)$, and $1056 \mathrm{~cm}^{-1}\left(\mathrm{v}_{1}\right)$ are attributed to the carbonate anion environment $[42,43]$. The bands recorded in the lowfrequency region of the spectrum $\left(<700 \mathrm{~cm}^{-1}\right)$ are assigned to the translational mode of M$\mathrm{O}-\mathrm{H}$ and $\mathrm{M}-\mathrm{OH}-\mathrm{M}$ vibrations. Significant difference in these bands was observed with an increase in Ce concentration of synthesized LDHs. The FT-IR spectra of the LDH-1 to LDH-3 showed the typical bands of the hydrotalcite-like compounds [42]. In case of LDH4 to LDH-6 a new band was observed at $3681 \mathrm{~cm}^{-1}$, which corresponds to non bonded -OH group vibrations for $\mathrm{M}(\mathrm{OH})_{\mathrm{x}}$. 


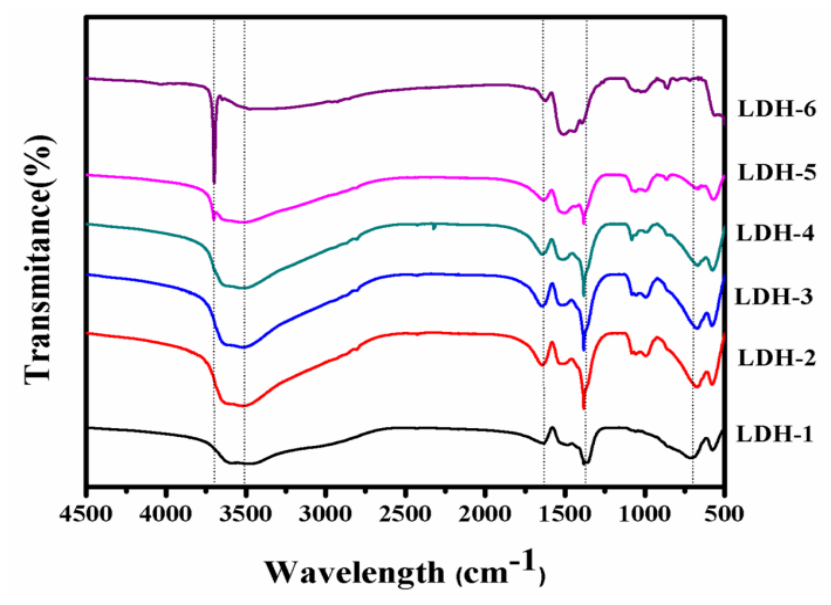

Fig. 2. FT-IR spectra of synthesized $\mathrm{Mg}_{3} \mathrm{Fe}_{\mathrm{x}} \mathrm{Ce}_{1-\mathrm{x}} \mathrm{LDHs}$.

\subsection{Transmission electron microscopy}

The influence of Ce concentration on the crystal shape and size was clearly observed from the morphology of all synthesized materials (Fig. 3). The TEM images (Fig. 3A, B, and C) showed that the LDHs (LDH-1 to LDH-3) are composed of crystallites with the typical plate like morphology and often hexagonal shaped [39]. However, in LDH-4 and LDH-5 (Fig. $3 \mathrm{D}$ and E) particles of irregular shape with agglomerated small particles of [Ce(OH)4] on surface and edges of crystallites were observed. In case of LDH-6 (Fig. 3 F) the layered structure was absent with significant increase in agglomerated particles. The crystalline nature of the individual materials (LDH-1 to LDH-6) was further checked by selected area electron diffraction (SAED) patterns shown in the Fig. 3 (A, B, C, D, E and F). LDH-1 to LDH-3 samples showed good crystalline nature which decreased with increase in Ce concentration (LDH-4 to LDH-6) [44].
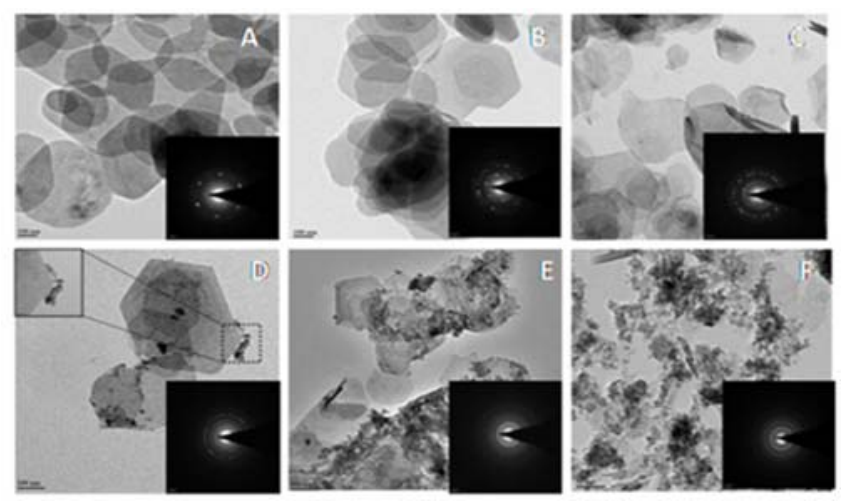
Fig. 3.TEM images and SAED patterns of synthesized $\mathrm{Mg}_{3} \mathrm{Fe}_{\mathrm{x}} \mathrm{Ce}_{1-\mathrm{x}} \mathrm{LDHs}(\mathrm{A}) \mathrm{LDH}-1$ (B) LDH-2 (C) LDH-3 (D) LDH-4 (E) LDH-5 and (F) LDH-6.

\subsection{Surface area measurements}

BET surface areas and textural properties of catalysts were determined by nitrogen adsorption-desorption isotherms and the values obtained are summarized in Table 1. The BET surface area, pore volume and pore size increased with increase in Ce concentration from LDH-1 to LDH-3. LDH-3 showed nearly two times more surface area $\left(136 \mathrm{~m}^{2} / \mathrm{g}\right)$ than parent LDH-1 $\left(67 \mathrm{~m}^{2} / \mathrm{g}\right)$. With further increase in Ce content from LDH-4 to LDH-6; slight decrease in surface area and pore volume was observed. This may be due to 1) distortion in layer structure because of incorporation of excess amount of Ce, 2) Deposition of the agglomerated particles formed during precipitation conditions or their incorporation into the pore system of LDH respectively [45].

\subsection{Basicity measurement}

The nature of the active species present on the surface is important for establishing the properties of the catalyst. Consequently, basic properties of the catalysts were determined by benzoic acid titration of the basic sites in the presence of $\mathrm{pH}$ indicators and the results are presented in Table 1. The strong basic sites correspond to $-\mathrm{OH}$ sites present in brucite like structure and weak basic sites correspond to carbonate species and simple metal bonded $-\mathrm{OH}$ group $\left[\mathrm{M}(\mathrm{OH})_{\mathrm{x}}\right]$ present in synthesized materials $[46,47]$. From the Table 1 it can be clearly observed that the weak basic sites increased consistently with increase in Ce concentration LDH-1 to LDH-6. However strong basic sites increased with increase in Ce concentration from LDH-1 to LDH-3 and decreased with further increase in Ce concentration for LDH-4 to LDH-6. Parent LDH-1 has less number of strong and weak basic sites than Ce incorporated LDHs (LDH-2 and LDH-3). The increase in basic properties and also the increase in surface area for Ce incorporated LDHs (LDH-2 and LDH-3) can be correlated to exchange of Fe with Ce having lower electronegetivity [39].

\subsection{X-ray photoelectron spectroscopy}

The XPS spectra of Ce $3 \mathrm{~d}$ and $\mathrm{O} 1 \mathrm{~s}$ have been analyzed in detail (see supporting information pages S5-S7), in order to understand the effect of Ce concentration on surface active sites $(-\mathrm{OH})$ of synthesized LDHs. Figure S2 shows the XPS spectra of Ce $3 \mathrm{~d}$ for the synthesized 
LDHs (LDH-2 to LDH-5). XPS spectra of the Ce 3d core level can be resolved into 10 groups; and the representative example of the fitting procedure for the Ce3d of LDH- 6 is presented in Fig. 4 [48]. The Ce 3d spectrum of all samples (LDH-2 - LDH-6) indicated presence of mixed valence states of $\mathrm{Ce}^{3+}$ and $\mathrm{Ce}^{4+}$. The peaks attributed to $\mathrm{O} 1 \mathrm{~s}$ are observed at $530.6 \mathrm{eV}$ and $532.3 \mathrm{eV}$ (Fig. S3). The first one, with a very low intensity is characteristic of $\mathrm{O}^{2-}$ (attributed to carbonate species) designated as " $\mathrm{O}_{\beta}$ ”, whereas the high intensity second peak corresponds to the oxygen species in hydroxide form (-OH) designated as " $\mathrm{O} \alpha$ ” [49]. The quantitative analysis of the Ce $3 \mathrm{~d}$ and $\mathrm{O} 1 \mathrm{~s}$ XPS peaks for the samples is summarized in Table S2 and includes percentage concentrations of the $\mathrm{Ce}^{4+}$, $\mathrm{Ce}^{3+}, \mathrm{O}_{\alpha}$ and $\mathrm{O}_{\beta}$ species present on the material surface. From the Table $\mathrm{S} 2$ it was clearly observed that the gradual increase in $\mathrm{Ce}^{4+}$ concentration has taken place from LDH-4 to LDH-6 (60.2 to $69.1 \%)$ with increase in Ce concentration. This indicates that increase in Ce concentration has led to increase in $\mathrm{Ce}^{4+}$ present on the surface in the form of $\mathrm{Ce}(\mathrm{OH})_{4}$. The amount of $\mathrm{Ce}$ in $\mathrm{LDH}$ structure also affects the concentration of surface $\mathrm{O}_{\alpha}$ and $\mathrm{O}_{\beta}$ (Table S2). Parent compound (LDH-1) has surface $\mathrm{O}_{\alpha}$ concentration of $78.3 \%$ and increased with Ce loading for materials having LDH structure intact ( $86.9 \%$ for LDH-2 and $87.2 \%$ for LDH-3). Further increase in ceria concentration (LDH-4 to LDH-6) led to marginal drop in the concentration of surface $\mathrm{O}_{\alpha}(85.2$ to $81.6 \%)$ with rise in $\mathrm{O}_{\beta}(14.3$ to $18.4 \%$ ). Probably with increase in Ce concentration (LDH-4 to LDH-6) the distortion in the layer structure occurred; which led to marginal decrease in surface $\mathrm{O}_{\alpha}$ group and relatively $\mathrm{O}_{\beta}$ species are exposed to the sample surface.

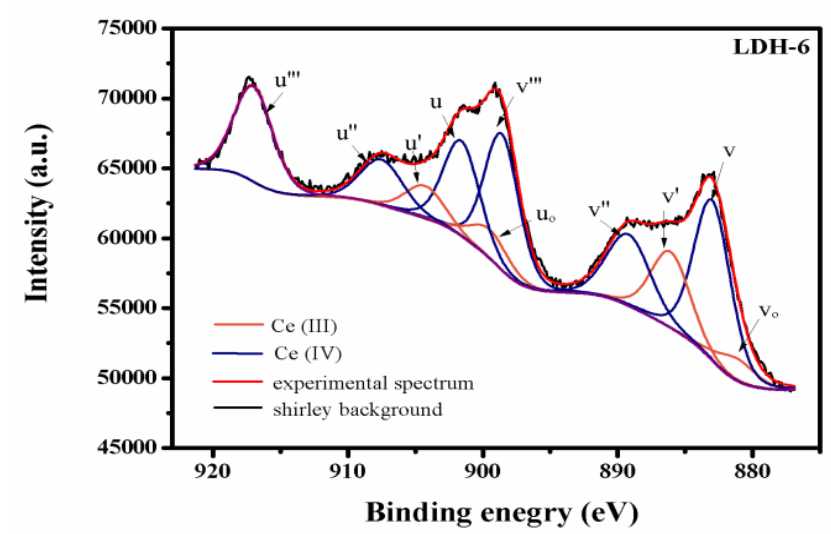

Fig. 4. Representative example of the fitting procedure for the Ce $3 \mathrm{~d}$ peak of LDH-6. 
The detailed characterization results demonstrate that the structural, textural and chemical properties of the LDHs can be fine-tuned by doping with appropriate amount of another trivalent metal such as Ce. XRD, FT-IR and TEM analysis (Fig. 1, 2 and 3) clearly showed that LDH-1 to LDH-3 formed well defined LDH structure with high crystallinity (better ordering of brucite sheets). No other phase was detected, implying that Ce was well incorporated in the prepared LDHs. Among which LDH-3 showed high surface area and pore volume with high amount of strong basic sites present on LDH surface (Table 1). Further with increase in Ce concentration (LDH-4 to LDH-6) distortion in layer structure was observed from XRD, TEM and XPS analysis. This may be due to the isomorphic substitution of Fe by large ionic radii cation Ce. In case of LDH-4 and LDH-5 precipitation of $\mathrm{Ce}(\mathrm{OH})_{4}$ on surface was clearly observed and confirmed by XRD, TEM and FT-IR analysis. LDH structure was totally absent for LDH-6 (Fe:Ce = 0:1) and mixed hydroxide, carbonate phases were observed. These observations are found to be consistent with surface area, pore volume and strong basic site densities (hydroxyl groups present in the brucitelike structure) of LDHs, which marginally decreased from LDH-4 to LDH-6. Distortion in LDH structure results in the decrease in surface area, pore volume and structure bonded $\mathrm{OH}$ groups (strong basic sites). According to literature reports, the structure bonded -OH group are strong basic in nature than simple metal bonded-OH groups $\left(\mathrm{Mg}(\mathrm{OH})_{2}\right.$ or $\mathrm{Ce}(\mathrm{OH})_{4}[46,47]$. The decrease in the intensity of FT-IR band at $3500 \mathrm{~cm}^{-1}(-\mathrm{OH})$ for LDH4 to LDH-6 (Fig. 2); also supports this observation. Characterization of the catalysts indicated that layered structure was intact till LDH-3 and LDH-3 was found to be material with higher surface area, pore volume and higher amount of strong basic sites.

\subsection{Catalyst activity}

Ce promoted $\mathrm{Mg}_{3} \mathrm{Fe}_{\mathrm{x}} \mathrm{Ce}_{1-\mathrm{x}} \mathrm{LDHs}$ were investigated for the transesterification reaction and the results are presented in Fig. 5. From the results, it was clearly observed that catalyst activity trend is in the order of LDH- $6<\mathrm{LDH}-5<\mathrm{LDH}-1<\mathrm{LDH}-4<\mathrm{LDH}-2<\mathrm{LDH}-3$. Catalyst activity increased with increase in Ce concentration up to a level and decreased with further increase in Ce concentration. Among all synthesized catalysts LDH-3 showed maximum EC conversion (87\%) and DMC selectivity (100\%). It should be noted that both binary systems LDH-1 (Mg $: \mathrm{Fe})$ and LDH-6 $\left(\mathrm{Mg}_{3}: \mathrm{Ce}\right)$ were found to be less active as compared 
to LDH-3 (EC conversion 62 and $26 \%$ with DMC selectivity 93 and $48 \%$ respectively). Thus the activity observed was strongly dependent on the Ce concentration in the synthesized LDHs. The observed activity trend was found to be in good agreement with physicochemical properties of synthesized LDHs. Thus, EC conversion was lower with LDH-1 and increased with Ce concentration (LDH-2<LDH-3). Best results were obtained with LDH-3 ( $\left.\mathrm{Mg}_{3} \mathrm{Fe}_{0.85} \mathrm{Ce}_{0.15}\right)$ having highest amount of strong base sites present on $\mathrm{LDH}$ surface with high surface area and pore volume as compared to other LDHs. With further increase in Ce concentration (LDH-4-LDH-6) strong basic sites, surface area and pore volume decreased and could be attributed to the formation and deposition of $\mathrm{Ce}(\mathrm{OH})_{4}$ phase and distorted nature of layered structure of LDHs; which

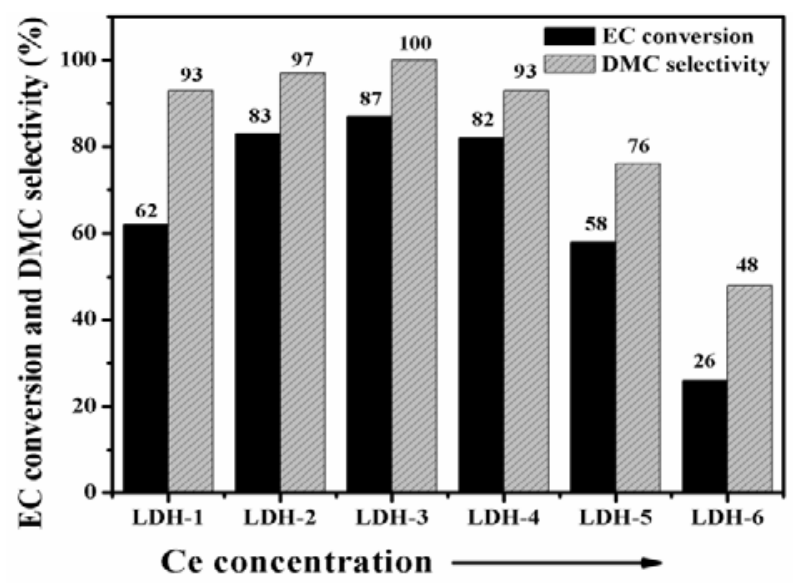

Fig.5. Effect of Ce concentration in $\mathrm{Mg}_{3} \mathrm{Fe}_{\mathrm{x}} \mathrm{Ce}_{1-\mathrm{x}} \mathrm{LDHs}$ towards the transesterification reaction. Reaction conditions: $\mathrm{EC}: \mathrm{MeOH}$ molar ratio: 1:10, catalyst: $2.5 \mathrm{wt} \%$ relative to $\mathrm{EC}$, reaction time: $3 \mathrm{~h}$, temperature: $70^{\circ} \mathrm{C}$.

reduced the catalyst activity. This is in accordance with the results obtained by Kannan et al. for hydroxylation of phenol using CoNiAl ternary LDH as catalyst [50]. They concluded that strong basic sites (hydroxyl groups) play an important role in catalytic activity and the appropriate geometry and concentration of both the metal cations in a well ordered two dimensional lattice could be responsible for the activity observed. The most active catalyst (LDH-3) was taken for further study. Effect of $\mathrm{EC} / \mathrm{CH}_{3} \mathrm{OH}$ molar ratio on the transesterification reaction was investigated using LDH-3 catalyst (Fig. 6A). From Fig. 6A it was clearly observed that the $\mathrm{EC} / \mathrm{CH}_{3} \mathrm{OH}$ feed molar ratio had a significant impact on the transesterification reaction. Transesterification of $\mathrm{EC}$ and methanol $(\mathrm{EC}+\mathrm{MeOH} \rightarrow \mathrm{DMC}$ $+\mathrm{EG})$ is an equilibrium controlled reaction and hence excess methanol is required to shift 
the equilibrium towards right and achieve high selectivity to DMC as the product [16-19]. EC conversion (63-87\%) and DMC selectivity (92-100\%) increased gradually with increase in the feed molar ratio of $\mathrm{EC} / \mathrm{CH}_{3} \mathrm{OH}$ from $1: 5$ to $1: 10$. Further increase in $\mathrm{EC} / \mathrm{CH}_{3} \mathrm{OH}$ ratio from 1:15-1:20 had marginal effect on EC conversion (92-94\%) with $100 \%$ selectivity to DMC. The effect of reaction temperature $\left(30-70^{\circ} \mathrm{C}\right)$ also has a significant impact on the activity and selectivity of the reaction. Thus at $30^{\circ} \mathrm{C} \mathrm{EC}$ conversion of $18 \%$ with $47 \%$ selectivity to DMC was observed. EC conversion and DMC selectivity increased with increase in temperature and $51 \%$ conversion of EC with $66 \%$ selectivity to DMC was observed at $50^{\circ} \mathrm{C}$. Low selectivity to DMC was because of the formation of HEMC as major product. . Results indicate that higher temperature as well as higher EC:methanol mole ratio are necessary for the conversion of intermediate HEMC to DMC. Zhang et al. [12] also have observed similar results in the transesterification of EC and methanol using carboxylic functionalized imidazolium salt as the catalyst Best results (87\% EC conversion and 100\% DMC selectivity) were obtained at $70^{\circ} \mathrm{C}$. The effect of catalyst loading is presented in Fig. 7. Activity was low at a catalyst loading of $0.6 \mathrm{wt} \%$ and $69 \%$ conversion of EC with $93 \%$ selectivity to DMC was observed. Activity and selectivity to DMC increased with catalyst loading and $87 \%$ conversion of EC with $100 \%$ selectivity to DMC was observed at a catalyst loading of $2.5 \mathrm{wt} \%$. The improved performance observed with increase in catalyst loading can be attributed to increase in basic sites available for the reaction. Further increase in catalyst loading ( 2.5 to $5 \mathrm{wt} \%$ ) had marginal effect on EC conversion (87-89\%) showing high selectivity to DMC (100\%). Catalyst loading of $2.5 \mathrm{wt} \%$ was taken as optimum for this reaction and used for further study. 

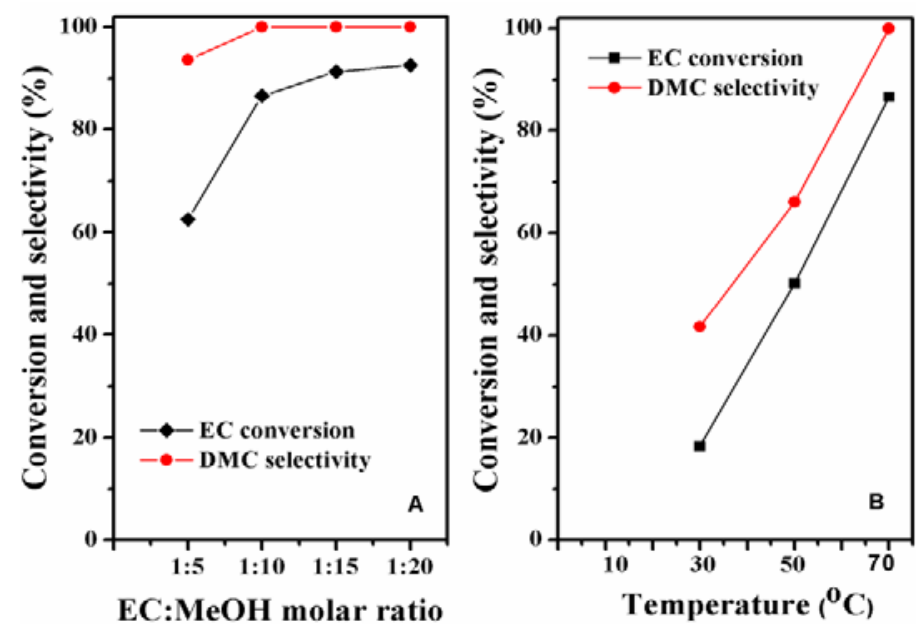

reaction temperature $(\mathrm{B})$ on the catalytic transesterification. Reaction conditions: (A) EC: MeOH: 1:5-1:20, catalyst: $2.5 \mathrm{wt} \%$ relative to $\mathrm{EC}$, reaction time: $3 \mathrm{~h}$, temperature: $70^{\circ} \mathrm{C}$. (B) $\mathrm{EC}: \mathrm{MeOH}: 1: 10$, catalyst: $2.5 \mathrm{wt} \%$ relative to $\mathrm{EC}$, reaction time: $3 \mathrm{~h}$, temperature: $30-70^{\circ} \mathrm{C}$.

Best result was obtained with catalyst loading of $2.5 \mathrm{wt} \%$ and was used for further study. All the experiments in this study were carried out with sampling in a time range of 1-5 $\mathrm{h}$.

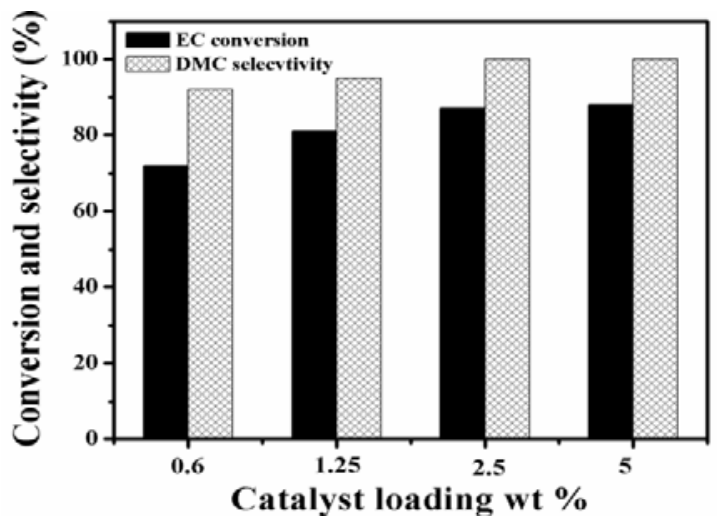

Fig.7. Effect of catalyst loading on transesterification of EC with methanol using LDH-3. Reaction conditions: EC: $\mathrm{MeOH}: 1: 10$, catalyst: $0.6-5 \mathrm{wt} \%$ relative to $\mathrm{EC}$, reaction time: $3 \mathrm{~h}$, temperature: $70^{\circ} \mathrm{C}$.

However, since the data is exhaustive; the detailed parametric study data with results at different time intervals is presented in supporting information (Fig. S4-S6).

Finally typical conversion/selectivity Vs time plot under optimized reaction conditions using LDH-3 catalyst is presented in Fig. 8. EC conversion and DMC selectivity increased, while HEMC selectivity decreased with increase in reaction time. Maximum EC conversion $(87 \%)$ and DMC selectivity $(100 \%)$ was observed at $3 \mathrm{~h}$ reaction time. Further prolonging 
the reaction time had no positive effect on EC conversion indicating that the reaction has reached the equilibrium [17]. Lower selectivity of DMC observed at intermediate time intervals is due to the formation of HEMC as intermediate product.

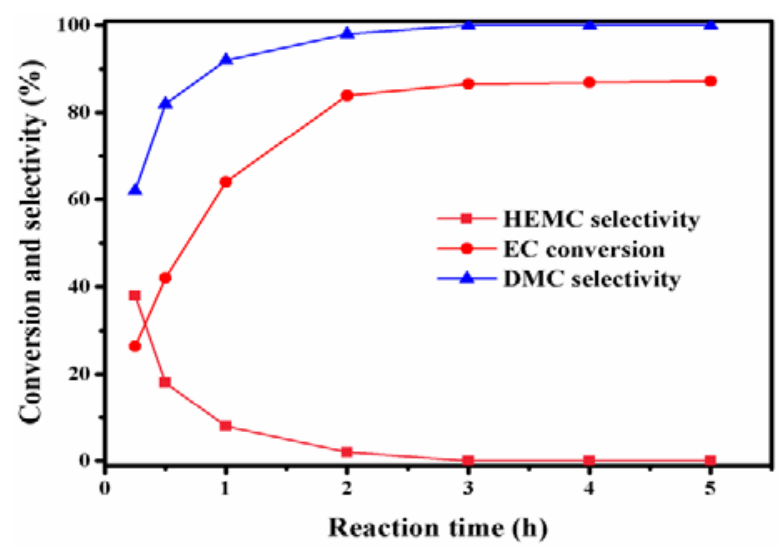

Fig.8. Effect of reaction time on EC conversion and DMC selectivity. Reaction conditions: EC: MeOH: 1:10, catalyst: $2.5 \mathrm{wt} \%$ relative to $\mathrm{EC}$, reaction time: $0.5-5 \mathrm{~h}$, temperature: $70^{\circ} \mathrm{C}$.

After optimization of reaction conditions with $\mathrm{Mg}_{3} \mathrm{Fe}_{0.85} \mathrm{Ce}_{0.15}$ (LDH-3) it was decided to investigate the effect of incorporation of other trivalent metals (instead of Ce) on the performance of the catalyst. For this purpose LDHs were prepared by varying M(III) [where $\mathrm{M}(\mathrm{III})=\mathrm{La}, \mathrm{Sm}, \mathrm{Y}$ and $\mathrm{Cr}]$ by keeping the molar ratio of 3:0.85:0.15 constant and tested for transesterification of EC with methanol under identical reaction conditions. From the Table 2 it was clearly observed that doping of different trivalent metal cations in parent LDH-1 ( $\left.\mathrm{Mg}_{3}: \mathrm{Fe}\right)$ affected the EC conversion and DMC selectivity significantly. Activity and selectivity followed in the order of $\mathrm{La} \approx \mathrm{Ce}>\mathrm{Sm}>\mathrm{Y}>\mathrm{Cr}$. Among all LDHs $\mathrm{Mg}_{3} \mathrm{Fe}_{0.85} \mathrm{Ce}_{0.15}$ (LDH-3) showed best activity and selectivity for this reaction. The results were found to be consistent with the electro negativities of the metal cations $(1.1 \approx 1.12$ $<1.17<1.22<1.66$ respectively). Incorporation of third cation which has low electronegativity results in the increase in basic property of LDH and leads to better activity [37]. The difference in the electronegativities of La and Ce is very small and expectedly the catalyst activities observed were comparable. Thus Ce incorporated $\mathrm{Mg}_{3}: \mathrm{Fe} \mathrm{LDH}$ was found to be best catalyst for transesterification reaction. 
Table 2. Effect of different metal cation $\mathrm{Mg}_{3}: \mathrm{Fe}_{0.85}: \mathrm{M}_{0.15}$ for transesterification reaction of $\mathrm{EC}$ with $\mathrm{MeOH}$

\begin{tabular}{ccc}
\hline Catalyst & $\begin{array}{c}\mathrm{EC} \\
\text { conversion } \\
(\%)\end{array}$ & $\begin{array}{c}\text { DMC } \\
\text { selectivity } \\
(\%)\end{array}$ \\
\hline $\mathrm{Mg}_{3}: \mathrm{Fe}_{1}$ & 62 & 94 \\
$\mathrm{Mg}_{3}: \mathrm{Fe}_{0.85}: \mathrm{La}_{0.15}$ & 85 & 99 \\
$\mathrm{Mg}_{3}: \mathrm{Fe}_{0.85}: \mathrm{Ce}_{0.15}$ & 87 & 100 \\
$\mathrm{Mg}_{3}: \mathrm{Fe}_{0.85}: \mathrm{Sm}_{0.15}$ & 81 & 95 \\
$\mathrm{Mg}_{3}: \mathrm{Fe}_{0.85}: \mathrm{Y}_{0.15}$ & 67 & 82 \\
$\mathrm{Mg}_{3}: \mathrm{Fe}_{0.85}: \mathrm{Cr}_{0.15}$ & 56 & 78
\end{tabular}

Reaction conditions : EC: $\mathrm{MeOH}$ molar ratio: 1:10, Catalyst: $2.5 \mathrm{wt} \%$ relative to EC, Reaction time: $3 \mathrm{~h}$, Temperature: $70^{\circ} \mathrm{C}$.

\subsection{Catalyst stability}

To check the stability of the catalyst recycle experiments were carried out and the results are presented in Fig. 9. It was observed that the catalyst retained its original activity and selectivity for seven recycle experiments indicating excellent stability. Further to check whether the catalyst leached out in reaction mixture; reaction was carried out by hot filtration and the results are summarized in the Fig. S7.

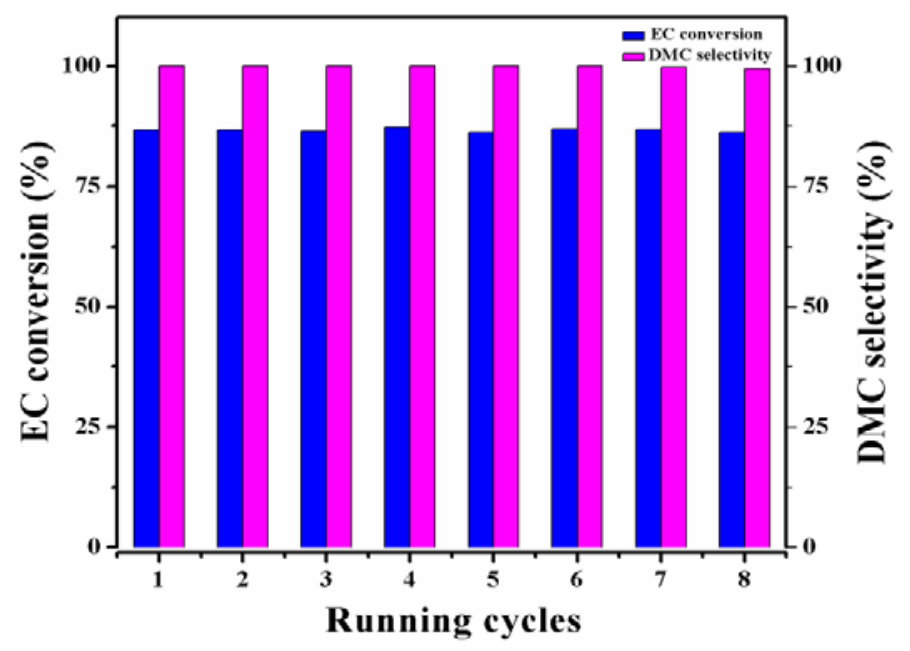


Fig. 9. Catalyst recycles study, Reaction conditions: EC: MeOH: 1:10, catalyst: $2.5 \mathrm{wt} \%$ relative to EC, reaction time: $3 \mathrm{~h}$, temperature: $70^{\circ} \mathrm{C}$.

It was found that in the absence of the catalyst, there was no further increase in the EC conversion, which indicated that there was no leaching and transesterification is purely a heterogeneously catalyzed reaction. At the end of the 7 recycle experiments the XRD analysis of the used catalyst was carried out (Fig. S8). No change in the XRD pattern was observed for used catalyst, indicating high stability of the catalyst (LDH-3) towards transeserification reaction. From the literature mixed metal oxides were active catalysts for DMC synthesis and high reaction temperature $\left(100-180^{\circ} \mathrm{C}\right)$ and catalyst loading $(10-25$ $w t \%$ of EC) was required in these cases [15-17]. The catalysts were stable up to 4-5 recycle experiments; however activation of the recovered catalyst at higher temperature was necessary before each reuse. Ternary $\mathrm{Mg}_{3} \mathrm{Fe}_{0.85} \mathrm{Ce}_{0.15}$ ( $\mathrm{LDH}-3$ ) catalyst developed in the present work does not require any pre-treatment and could be recycled up to seven times without loss in EC conversion and DMC selectivity under mild reaction conditions.

\subsection{Catalytic mechanism}

Mechanism of the transeterification of EC with methanol has been discussed in several reports [25, 11, and 23]. Hydroxy groups (strong basic sites) present on LDH surface play an important role in transesterification reaction which was studied by many researchers using various spectroscopic techniques. According to Roeffaers et al. transesterification of 5-carboxyfluorescein with 1-butanol over [ $\mathrm{Li}-\mathrm{Al}]$ layered double hydroxide catalyst occurs on the basal planes of the outer crystal surface whereas the hydrolysis reaction takes place on the crystal edges [51]. Additionally, Greenwell et al. have presented evidence form density functional theory (DFT) calculations that surface bonded $-\mathrm{OH}$ anion may directly participate in the catalytic reaction and act more than the simple metal hydroxyl group [52]. In the present work, significant improvement in EC conversion was observed with incorporation of $\mathrm{Ce}$ in the $\mathrm{Mg}_{3}-\mathrm{Fe} \mathrm{LDH}$ (LDH-3). Detailed characterization of the catalyst indicated the presence of more amount of active sites (-OH group) on LDH surface with high surface area compared to parent $\mathrm{Mg}_{3}-\mathrm{Fe} \mathrm{LDH}$ (LDH-1). Taking into account the literature reports and results observed in the present work a probable mechanism has been 
proposed (scheme 2); where the -OH species and metal cations present above the LDH surface act as strong base and Lewis acid sites respectively.

The reaction begins with the abstraction of proton from methanol on $-\mathrm{OH}$ sites of $\mathrm{LDH}$ to

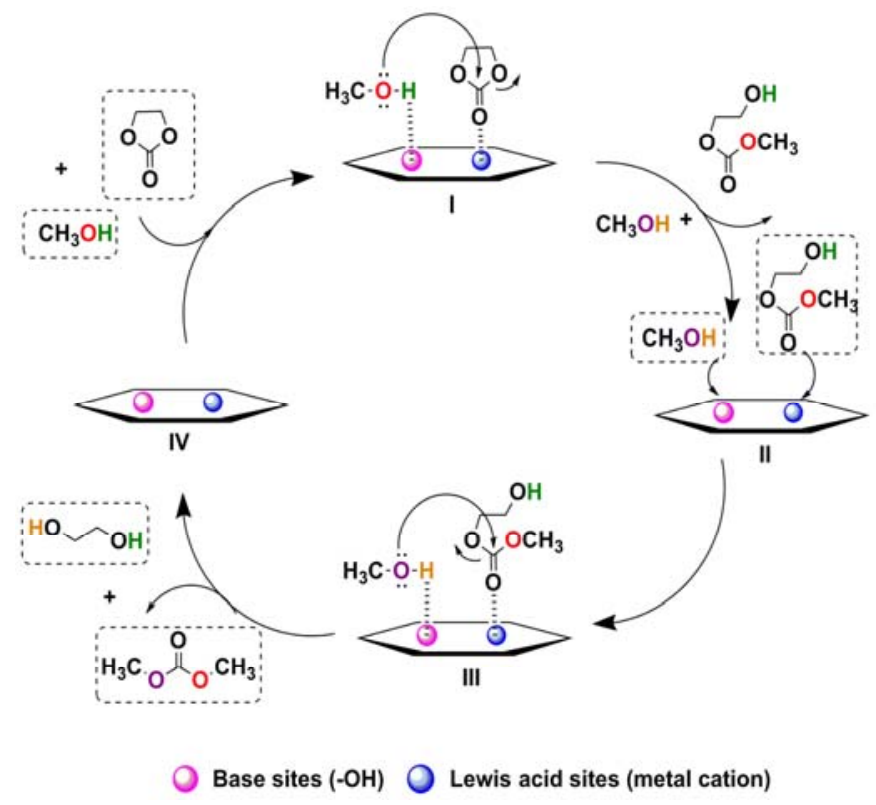

Scheme 2. A possible mechanism for the transesterification of ethylene carbonate with methanol catalyzed by LDH3

generate methoxy anion and activation of carbonyl carbon of EC on Lewis acid sites of LDHs to generate relatively charged carbonyl carbon (step I). Generated methoxy anion attacks on the activated carbonyl carbon of EC to form HEMC as the intermediate product (step II). In next step (III) another methanol molecule will attack in similar fashion to form DMC and EG as the final products and the catalyst is regenerated back (step IV). The formation of HEMC as an intermediate product was observed at low $\mathrm{EC}$ : $\mathrm{CH}_{3} \mathrm{OH}$ ratios (Fig. 6A) and at low reaction temperature (Fig.6B) leading to poor selectivity to the target DMC.

\section{Conclusions}

Transesterification of EC with methanol to DMC was investigated in detail using $\mathrm{Mg}_{3} \mathrm{Fe}_{\mathrm{x}} \mathrm{Ce}_{1-\mathrm{x}}$ ternary $\mathrm{LDH}$ as the catalyst. The LDHs were synthesized by varying $\mathrm{Fe}: \mathrm{Ce}$ molar ratio in a range of 1:0 to 0:1. Both the end members of this series $\mathrm{Mg}_{3} \mathrm{Fe}(\mathrm{LDH}-1)$ and $\mathrm{Mg}_{3} \mathrm{Ce}$ (LDH-6) showed lower catalytic activity and selectivity to DMC. The 
significant increase in EC conversion and DMC selectivity was observed with appropriate concentration of Ce present in LDH structure. The activity varied in the order LDH$6<\mathrm{LDH}-5<\mathrm{LDH}-1<\mathrm{LDH}-4<\mathrm{LDH}-2<\mathrm{LDH}-3$. Among the synthesized catalysts LDH-3 (Fe:Ce molar ratio: 0.85:0.15) showed best catalytic performance (87\% EC conversion with 100\% DMC selectivity) under mild reaction conditions. LDH-3 was found truly heterogeneous catalyst and was recycled seven times without loss in catalytic activity and selectivity to DMC. The activity trend was found to be in good agreement with structural and surface basic properties of the synthesized LDHs. Various trivalent metals were also used to modify the $\mathrm{LDH}$ with composition $\mathrm{Mg}_{3} \mathrm{Fe}_{0.85} \mathrm{M}_{0.15}$ [where $\mathrm{M}(\mathrm{III})=\mathrm{La}, \mathrm{Sm}, \mathrm{Y}$ and $\mathrm{Cr}]$ and the activity trend followed in order of $\mathrm{La} \approx \mathrm{Ce}>\mathrm{Sm}>\mathrm{Y}>\mathrm{Cr}$. The best results were obtained with Ce modified $\mathrm{Mg}_{3}: \mathrm{Fe} \mathrm{LDH}\left(\mathrm{Mg}_{3} \mathrm{Fe}_{0.85} \mathrm{Ce}_{0.15}\right)$ as the catalyst. The results were found to be in good agreement with the electronegativities of incorporated third metal cations $[\mathrm{M}(\mathrm{III})]$. To the best of our knowledge this is the first report on the use of $\mathrm{Mg}_{3} \mathrm{Fe}_{0.85} \mathrm{Ce}_{0.15}$ ternary $\mathrm{LDH}$ as a catalyst for this reaction.

\section{Acknowledgement}

Authors would like to acknowledge partial financial support to the work from the project CSC0123 funded by CSIR-Delhi, India. NTN would like to acknowledge CSIR-Delhi, India for fellowship grant.

\section{References}

1. Huang S, Yan B, Wang S, Ma X (2015) Chemical Society Reviews 44:3079

2. Tundo P, Selva M (2002) Accounts of chemical research 35:706

3. Shaikh AAG, Sivaram S (1996) Chemical reviews 96:951

4. Pacheco MA, Marshall CL (1997) Energy \& Fuels 11:2

5. Rounce P, Tsolakis A, Leung P, York APE (2010) Energy \& Fuels 24:4812

6. Babad H, Zeiler AG (1973) Chemical reviews 73:75

7. Drake IJ, Fujdata KL, Bell AT (2005) Journal of Catalysis 230:14

8. Fukuoka S, Tojo M, Hachiya H, Aminaka M, Hasegawa K (2007) POLYMER JOURNAL-TOKYO 39:91 
9. Fakhrnasova D, Chimento RJ, Medina F, Urakawa A (2015) ACS Catalysis 5:6284

10. Du GF, Guo H, Wang Y, Li WJ, Shi WJ, Dai B (2015) Journal of Saudi Chemical Society 19:112

11. Yang ZZ, Dou XY, Chanfreau SB (2010) Tetrahedron Letters 51:2931

12. Zhang SJ, Wang JQ, Sun J, Cheng WG, Shi CY, Dong K, Zhang XP (2012) Catalysis Science \& Technology, 2.5: 600

13. Xu J, Wu HT, Ma CM, Xue B, Li YX, Cao Y (2013) Applied Catalysis A: General $464: 357$.

14. Kim DW, Lim DO, Cho DH, Koh JC, Park DW (2011) Catalysis today 164:556

15. Bhanage BM, Fujita SI, Ikushima Y, Arai M (2001) Applied Catalysis A: General 219:259

16. Murugan C, Bajaj HC (2013) Indian journal of chemistry 52A:459

17. Kumar P, Srivastava VC, Mishra IM (2015) Energy \& Fuels 29:2664

18. Unnikrishnan P, Srinivas D (2015) Journal of Molecular Catalysis A: Chemical 398:42

19. Sankar M, Satav S, Manikandan P (2010) ChemSusChem 3:575

20. Bhanage BM, Fujita SI, Ikushima Y, Torii K , Arai M (2003) Green Chemistry 5:71

21. Tatsumi T, Watanabe Y, Koyano KA (1996) Chemical Communications 19:2281

22. Stoica G, Abello SN, Perez-Ramirez J (2009) Applied Catalysis A: General 365:252

23. Xu J, Long KZ, Chen T, Xue B, Li YX, Cao Y Catalysis Science \& Technology (2013) $3: 3192$

24. Watanabe Y, Tatsumi T (1998) Microporous and mesoporous materials 22:399

25. Murugan C, Bajaj HC (2010) Indian journal of chemistry 49A:1182

26. Cavani F, Trifiro F, Vaccari A (1991) Catalysis today 11:173

27. Nishimura S, Takagaki A, Ebitani K (2013) Green Chemistry 15:2026

28. Cantrell DG, Gillie LJ, Lee AF, Wilson K (2005) Applied Catalysis A: General 287: 183

29. Jana SK, Wu P , Tatsumi T (2006) Journal of Catalysis 240:268

30. Liu Z, Li L, Chen Y, Zhang Y (2014) Acta Geologica Sinica (English Edition) 88:354

31. Malinowski S, Szczepaoska S (1963) Journal of Catalysis 2:310

32. Zavoianu R, Birjega R, Pavel OD, Cruceanu A, Alifanti M (2005) Applied Catalysis A: General 286:211 
33. Triantafyllidis KS, Peleka EN, Komvokis VG, Mavros PP (2010) Journal of colloid and interface science 342:427

34. Peng F, Luo T, Yuana Y (2014) New J. Chemistry 38:4427

35. Wang D, Zhang X, Ma J (2016) Catalysis Science \& Technology 6.5: 1530.

36. Tang K, Zhang J, Wang W, Wang S, Guo J, Yang Y (2015) CrystEngComm 17:2690

37. Ansari AA, Kaushik A (2010) Journal of Semiconductors 31:033001

38. Z Wang, P Fongarland, G Lu, N Essayem Journal of Catalysis, (2014) 318:108.

39. Pavel OD, Cojocaru B, Angelescu E, (2011) Applied Catalysis A: General 403:83

40. Zhao Y, Li JG, Fang F, Chu N, Ma H, Yang X (2012) Dalton Transactions 41:12175

41. Caravaggio GA, Detellier C, Wronski Z Journal of Materials Chemistry (2001) 11:912

42. Jun H, Zhiliang Z, Hongtao L, Yanling Q (2014) RSC Advances 4:5156

43. Perez MR, Crespo I, Ulibarri MA, Barriga C, Rives V, Fernandez JM (2012) Materials Chemistry and Physics 132:375

44. Baliarsingh N, Mohapatra L, Parida K Journal of Materials Chemistry A (2013) 1:4236

45. Wang D, Zhang X, Ma J, Yu H, Shena J, Wei W (2015) Catal. Sci. Technol 6:1530

46. Navajas A, Campo I, Arzamendi G, Hernajndez WY, Bobadilla LF, Centeno MA, Odriozola JA , Gandia LM (2010) Applied Catalysis B: Environmental 100:299

47. Xi Y, Davis RJ (2008) Journal of Catalysis 254:190

48. Hu Z, Liu X, Meng D, Guo Y, Guo Y, Lu G (2016) ACS Catalysis 6:2265

49. Parida K, Satpathy M , Mohapatra L (2012) Journal of Materials Chemistry 22:7350

50. Rives V, Prieto O, Dubey A, Kannan S (2003) Journal of Catalysis 220:161

51. Roeffaers MBJ, Sels BF, Uji-i H, De Schryver FC, Jacobs PA, Hofkens J (2006) Nature 439:572

52. Greenwell HC, Stackhouse S, Coveney PV, Jones W The Journal of Physical Chemistry B (2003) 107:3476 